\title{
Understanding the unusual fluidity characteristics of high ash Indian bituminous coals
}

\author{
Bidyut Das $^{\mathrm{a}}$, A Suresh ${ }^{\mathrm{a}}$, Pratik Swarup Dash ${ }^{\mathrm{a}}$, Sanjay Chandra ${ }^{\mathrm{a}}$, Miguel Castro Díaz ${ }^{\mathrm{b}}$, Lee A. \\ Stevens ${ }^{\mathrm{b}}$, Colin E. Snape*b \\ a Tata Steel Limited, Burmamines, R\&D and Scientific Services, Jamshedpur 831 007, India \\ ${ }^{b}$ University of Nottingham, Faculty of Engineering, Energy Technologies Building, \\ Nottingham, NG7 2TU, UK \\ *Corresponding author. Email: colin.snape@ nottingham.ac.uk
}

\begin{abstract}
High-temperature rheometry and ${ }^{1} \mathrm{H}$ nuclear magnetic resonance (NMR) are two complementary techniques that have been used to investigate fluidity development quantitatively in the $<53 \mu \mathrm{m}$ and 53-212 $\mu \mathrm{m}$ size fractions of high ash Indian non-coking coals and imported non-coking, medium coking and good coking coals. It was found for the 53-212 $\mu \mathrm{m}$ size fraction of the Indian bituminous coal with higher ash content (30 wt $\%$ ) that, despite its high complex viscosity ( $\left.>10^{5} \mathrm{~Pa} . \mathrm{s}\right)$, the maximum concentration of fluid $\mathrm{H}$ was quite similar to that of the good coking coal (40\%). This Indian non-coking coal developed fluid $\mathrm{H}$ with the greatest mobility $\left(\mathrm{T}_{2 \mathrm{~L}}>150 \mu \mathrm{s}\right)$ in the coal series, regardless of the particle size fraction studied. The probable explanation for this abnormal behavior is that the mineral matter prevents bulk movement in the sample but the local mobility of the fluid phase is still high on the nanometer scale. Blending the two Indian non-coking coals with the highly fluid medium coking coal gave higher viscosities (i.e. lower fluidity) than predicted by the polymer blend rule, probably again due to the high mineral matter restricting bulk flow. This negative effect was less pronounced with the higher ash coal suggesting that the high mobility of the fluid entities in this coal might prevent the destruction of fluid entities evolving from the medium coking coal. Partial demineralization of the high ash Indian noncoking coal to $17 \mathrm{wt} \%$ through a sink-float method did not decrease the complex viscosity of this coal but reduced the maximum mobility of the fluid $\mathrm{H}$ to levels observed with the lower ash content $(20 \mathrm{wt} \%)$ Indian coal. Therefore, this reduction in mobility could be directly related to the mineral matter in the Indian non-coking coal.
\end{abstract}

\section{Keywords}

Non-coking coal, high ash coal, coal fluidity, coal viscosity. 


\section{Introduction}

The estimated coal reserves in India are of the order of 300 billion tones, with non-coking coals representing about 266 billion tones or $89 \%$ of these deposits [1]. Consequently, coking coal reserves in India are very limited and almost $40-50 \%$ of the total coking coal requirements of the Indian metallurgical industry must be imported. A great deal of interest has been paid in recent years to introduce Indian non-coking coals in coke oven blends to reduce costs without impairing the quality of the resultant coke. Coke quality is mainly defined by its cold and hot mechanical strengths and by its reactivity with $\mathrm{CO}_{2}$ at high temperatures. Parameters such as MICUM and IRSID indices (M40, M20, M10, I40, I20, I10), coke strength after reaction (CSR) and coke reactivity index (CRI) are used to evaluate coke quality. CSR and CRI parameters are the most important to assess the optimum amount of non-coking coals in an industrial blend. Carbonaceous additives and briquettes containing waste materials, such as tar decanter sludge and a pitch-like residue from the benzole distillation column, can be used to improve the coking properties of coal blends [2,3].

One major issue of most Indian coals is that they have a considerable proportion of fixed ash due to 'drift origin' of Gondwana formation in Permian age, being the ash content in run-ofmines coking coals as high as 30-45\% [4,5]. This fact has negative implications for coal fluidity and coke reactivity. Calcium-containing compounds deteriorate the swelling properties of coal [6,7] and potassium-containing compounds and sodium carbonate also decrease coal fluidity [8,9]. Higher concentrations of these metals also leads to higher reactivity of the coke [10], and thus, coke quality is negatively impacted. Therefore, the mineral matter in Indian non-coking coals must be reduced through beneficiation treatments to produce metallurgical coke suitable for blast furnace operation. Beneficiation of noncoking coal in India was not given due importance till the early 2000s due to its low value or not able to meet the cost of the process [11]. Currently, flotation is the only versatile beneficiation process in use for fine coal processing in India [12]. In a recent study, different organic compounds have been evaluated as frothers for de-ashing of Indian coking coals by froth flotation [13]. The chemical beneficiation of high ash Indian non-coking coal by alkali leaching has also been studied by Barma et al. [14]. However, most Indian coals are difficult to wash because of intermixing of organic matter and inerts, and as a result, the cut-off ash level for Indian coke making is between 13-18\% depending on the coal characteristics and available equipment in the washery [5].

To enable the conversion of Indian non-coking coal to coking coal, molecular level understanding at initial stage is quintessential to establish the relationship between coal structure and coking behavior (swelling, fluidity, dilation, reactivity, etc.) of coal. Hightemperature small-amplitude oscillatory-shear (SAOS) rheometry and high-temperature ${ }^{1} \mathrm{H}$ nuclear magnetic resonance (NMR) have been developed as complementary techniques to provide a more quantitative understanding of fluidity development during coal carbonization than is provided by empirical tests, such as the Gieseler plastometer and Arnu dilatometer [15-20]. SAOS rheometry can monitor not only the viscoelastic properties of coal pellets but also the expansion and collapse of the coal mass during carbonization. High-temperature ${ }^{1} \mathrm{H}$ NMR monitors fluidity development through the quantification of mobile (fluid) and rigid (solid) hydrogen in the sample as a function of temperature. The ${ }^{1} \mathrm{H}$ NMR signal can be separated into Gaussian and Lorentzian components, being equivalent to the proportions of hydrogen in rigid (solid) and fluid material, respectively. Further, the mobility of the fluid phase can be assessed from the peak widths of Lorentzian components. Thus, this technique complements rheometry, but essentially monitors molecular motion at a nanometer rather than at a bulk scale. In rheometry, medium to good coking coals typically reach complex 
viscosities $\left(\eta^{*}\right)$ of no more than $3 \times 10^{4} \mathrm{~Pa}$ s with phase angles below $70^{\circ}$. In high-

temperature ${ }^{1} \mathrm{H}$ NMR, these coals typically develop a maximum fluid $\mathrm{H}$ concentration between $35-50 \%$ with a lower concentration for good coking coals. The mobility of the fluid $\mathrm{H}$ in both cases is characterized by a spin-spin relaxation time $\left(\mathrm{T}_{2 \mathrm{~L}}\right)$ below $60 \mu$ s for fines $(<$ $53 \mu \mathrm{m})$ and below $90 \mu$ s for larger 53-212 $\mu \mathrm{m}$ size fractions, meaning that there is more restricted motion in the fines [21].

The main aim of this study is to understand the fluidity behavior of high-ash Indian noncoking coals to better utilize these coals in blends for coke making. In order to achieve this, their fluidity behavior in terms of viscoelasticity and fluid $\mathrm{H}$ evolution has been compared with reference good, medium and non-coking coals and the effect of partial demineralization through the sink-float method has been investigated.

\section{Material and Methods}

The characteristics of the two Indian non-coking coals A1 and A2 and the imported noncoking coal NC, medium coking coal MC and good coking coal GC used in this study are presented in Table 1. Coals A1 and A2 come from the same coal mine but from different seams. The ultimate analysis was performed using the standard test method ASTM D317615.

Table 1. Proximate and ultimate analyses and maceral composition of the coals studied.

\begin{tabular}{|c|c|c|c|c|c|}
\hline & A1 & $\mathrm{A} 2$ & $\mathrm{NC}$ & $\mathrm{MC}$ & GC \\
\hline Origin & India & India & Australia & USA & Australia \\
\hline Classification & Non-coking & Non-coking & Non-coking & Medium coking & Good coking \\
\hline Moisture (wt\%) & 7.1 & 6.6 & 2.1 & 1.1 & 1.7 \\
\hline Ash (wt\% db) & 13.5 & 36.6 & 9.6 & 7.2 & 9.4 \\
\hline $\mathrm{VM}(\mathrm{wt} \% \mathrm{db})$ & 32.7 & 32.1 & 21.7 & 29.2 & 22.3 \\
\hline $\mathrm{VM}$ (wt $\%$ daf) & 41.0 & 45.8 & 24.0 & 31.5 & 24.6 \\
\hline $\mathrm{C}(\mathrm{wt} \% \mathrm{daf})$ & 83.95 & 61.85 & 88.44 & 87.88 & 87.50 \\
\hline $\mathrm{H}(\mathrm{wt} \% \mathrm{daf})$ & 5.93 & 4.30 & 4.77 & 5.40 & 4.86 \\
\hline $\mathrm{N}(\mathrm{wt} \%$ daf $)$ & 1.71 & 1.26 & 1.53 & 1.67 & 1.69 \\
\hline $\mathrm{S}$ (wt\% daf) & 1.37 & 1.01 & 0.53 & 1.14 & 0.63 \\
\hline $\mathrm{O}$ (wt $\%$ daf) & 7.04 & 31.58 & 4.73 & 3.91 & 5.32 \\
\hline Vitrinite $(\%)$ & 46.0 & 61.0 & 50.7 & 75.1 & 47.4 \\
\hline Liptinite (\%) & 16.0 & 10.0 & 0 & 3.1 & 0 \\
\hline Inertinite $(\%)$ & 32.0 & 14.6 & 43.7 & 17.6 & 48.1 \\
\hline $\mathrm{MM}(\%)$ & 6.0 & 14.1 & 5.6 & 4.2 & 4.2 \\
\hline $\mathrm{R}_{0}(\%)$ & 0.40 & 0.40 & 1.15 & 1.05 & 1.17 \\
\hline
\end{tabular}

Table 2 presents the metal oxide composition of the ash in the Indian non-coking coals A1 and $\mathrm{A} 2$. 
Table 2. Concentration of metal oxides present in the ash of Indian non-coking coals A1 and A2 and their alkalinity indexes.

\begin{tabular}{lcc}
\hline Ash components & $\mathrm{A} 1$ & $\mathrm{~A} 2$ \\
\hline $\mathrm{Na}_{2} \mathrm{O}(\mathrm{wt} \% \mathrm{db})$ & 0.22 & 0.09 \\
$\mathrm{~K} 2 \mathrm{O}(\mathrm{wt} \% \mathrm{db})$ & 0.08 & 0.21 \\
$\mathrm{CaO}(\mathrm{wt} \% \mathrm{db})$ & 0.13 & 0.38 \\
$\mathrm{MgO}(\mathrm{wt} \% \mathrm{db})$ & 0.09 & 0.12 \\
$\mathrm{Fe}_{2} \mathrm{O}_{3}(\mathrm{wt} \% \mathrm{db})$ & 1.13 & 1.61 \\
$\mathrm{Al}_{2} \mathrm{O}_{3}(\mathrm{wt} \% \mathrm{db})$ & 4.27 & 8.24 \\
$\mathrm{SiO}_{2}(\mathrm{wt} \% \mathrm{db})$ & 13.23 & 18.90 \\
$\mathrm{Alkalinity} \mathrm{index} \%)$ & 1.91 & 2.66 \\
\hline
\end{tabular}

The alkalinity index (A.I.), which provides an indication of coal reactivity, is also displayed. The A.I. values were calculated using the following equation [10]:

A.I. $=\frac{\left[\mathrm{K}_{2} \mathrm{O}\right]+\left[\mathrm{Na}_{2} \mathrm{O}\right]+[\mathrm{CaO}]+[\mathrm{MgO}]+\left[\mathrm{Fe}_{2} \mathrm{O}_{3}\right]}{\left[\mathrm{SiO}_{2}\right]+\left[\mathrm{Al}_{2} \mathrm{O}_{3}\right]}$ Ash (\%)

The coal samples were manually crushed and sieved to obtain the $<53 \mu \mathrm{m}$ and 53-212 $\mu \mathrm{m}$ size fractions. Table 3 presents the percentages obtained for the two size fractions. 53-212 $\mu \mathrm{m}$ is the standard fraction used for rheometry and ${ }^{1} \mathrm{H}$ NMR tests as it generally gives very good reproducibility. The $<53 \mu \mathrm{m}$ fraction generally contains higher amounts of mineral matter [22,23], which can cause some reduction in fluidity development.

Table 3. Percentages of the two size fractions obtained from the coals after crushing and sieving.

\begin{tabular}{lllccc}
\hline Size fraction & A1 & A2 & NC & MC & GC \\
\hline$<53 \mu \mathrm{m}(\mathrm{wt} \%)$ & 42 & 42 & 40 & 53 & 37 \\
$53-212 \mu \mathrm{m}(\mathrm{wt} \%)$ & 58 & 58 & 60 & 47 & 63 \\
\hline
\end{tabular}

Solid-state ${ }^{13} \mathrm{C}$ NMR was carried out using a Bruker Avance magnet with a field strength of 4.7 Tesla (Larmor frequencies of $50 \mathrm{MHz}$ for ${ }^{13} \mathrm{C}$ and $200 \mathrm{MHz}$ for ${ }^{1} \mathrm{H}$ ) in conjunction with a Bruker solid-state ${ }^{13} \mathrm{C}$ NMR probe. Each coal sample was packed tightly into a zirconia rotor (7 mm diameter) and the amount of sample in the rotor was around $200 \mathrm{mg}$. The internal standard tetrakis-trimethylsilyl-silane (TKS) that produces a narrow peak at $3.5 \mathrm{ppm}$ was used to calibrate the spectra. The cross polarization $(\mathrm{CP})$ pulse sequence was used with magic angle spinning (MAS) to carry out the analyses. The rotor was spun at approximately $5000 \mathrm{~Hz}$ and CP/MAS analyses were carried out with 2500 scans, using an acquisition time of 0.05 seconds and a relaxation delay of 1.5 seconds. The aromaticity of the coals, which is expressed as the aromatic carbon divided by the total carbon in the sample, was determined by integrating the peak due to aromatic carbon and centered at $130 \mathrm{ppm}$, the peak due to aliphatic carbon and centered at around $30 \mathrm{ppm}$ and the spinning sideband at $230 \mathrm{ppm}$ that originates from aromatic carbon. Another spinning side band appears at $30 \mathrm{ppm}$ and overlaps the aliphatic carbon peak. This spinning sideband was considered to have identical area as the one positioned at $230 \mathrm{ppm}$ and was subtracted from the aliphatic carbon region to determine the aromaticity of the samples. 
Thermogravimetric analysis (TGA) and derivative thermogravimetric analysis (DTG) profiles of the $<53 \mu \mathrm{m}$ and 53-212 $\mu \mathrm{m}$ size fractions of Indian non-coking coals A1 and A2 were performed in a TA SDT Q600 instrument. Approximately $10 \mathrm{mg}$ of sample were heated from $30{ }^{\circ} \mathrm{C}$ to $900{ }^{\circ} \mathrm{C}$ at a heating rate of $3{ }^{\circ} \mathrm{C} / \mathrm{min}$ under a nitrogen flow rate of $100 \mathrm{ml} / \mathrm{min}$. Tests were carried out in duplicate to ensure the reproducibility of the results.

High-temperature rheometry tests were carried out in a Rheometrics RDA-III rheometer that was operated up to $500{ }^{\circ} \mathrm{C}$. Small-angle oscillatory-shear (SAOS) high torque rheometry tests were performed using $1.5 \mathrm{~g}$ of coal. The coal sample was compacted into a disc of 25 $\mathrm{mm}$ in diameter and about $2.6 \mathrm{~mm}$ in thickness using a hydraulic press operating under a force of 5 tones. The disc was then placed between the two serrated parallel plates of the rheometer. Heat was transferred to the sample using a furnace and the heating rates were ca. $80{ }^{\circ} \mathrm{C} / \mathrm{min}$ from $20{ }^{\circ} \mathrm{C}$ to $330{ }^{\circ} \mathrm{C}$ and $3{ }^{\circ} \mathrm{C} / \mathrm{min}$ from $330{ }^{\circ} \mathrm{C}$ to $500{ }^{\circ} \mathrm{C}$. All analyses were carried out in nitrogen atmosphere using a frequency of $6.28 \mathrm{rad} / \mathrm{s}(1 \mathrm{~Hz})$ and a strain of $0.1 \%$. The complex viscosity $\left(\eta^{*}\right)$, phase angle $(\delta)$ and change in plate gap $(\Delta \mathrm{L})$ were recorded as a function of temperature. The complex viscosity decreases and the phase angle increases as fluidity increases. The minimum complex viscosity values usually vary between $10^{3} \mathrm{~Pa}$.s and $10^{7} \mathrm{~Pa}$.s in coal. The phase angle can vary from $0^{\circ}$ for an ideal solid material (Hookean solid) to $90^{\circ}$ for an ideal viscous material (Newtonian fluid). The change in plate gap gives an indication of the extent of expansion and contraction of the coal mass during softening and resolidification.

High-temperature ${ }^{1} \mathrm{H}$ NMR tests were carried out in the Bruker Avance magnet operating at $200 \mathrm{MHz}$ in conjunction with a Doty Scientific ${ }^{1} \mathrm{H}$ NMR probe. The ${ }^{1} \mathrm{H}$ NMR probe was operated in nitrogen atmosphere up to temperatures around $500{ }^{\circ} \mathrm{C}$. Around $100 \mathrm{mg}$ of coal, in powder form, was placed inside a boron nitride container, which was closed with a cap with a hole that allows the volatiles to escape. The solid-echo pulse sequence was used for the acquisition of the NMR signal. The samples were heated from $330{ }^{\circ} \mathrm{C}$ to $500{ }^{\circ} \mathrm{C}$ at 3 ${ }^{\circ} \mathrm{C} / \mathrm{min}$ to mimic the conditions used in rheometry tests and 100 scans were recorded at intervals of $10^{\circ} \mathrm{C} / \mathrm{min}$. The NMR signals were deconvoluted into Lorentzian and Gaussian distribution functions, which correspond respectively to the fluid $\mathrm{H}$ and solid $\mathrm{H}$ (i.e. fluid and solid phases at the molecular level). The area of the Lorentzian peak relative to the total area represents the fraction of fluid hydrogen and the Lorentzian peak width at half-height $\left(\Delta \mathrm{H}^{1} / 2\right)$ is inversely proportional to the spin-spin relaxation time $\left(\mathrm{T}_{2 \mathrm{~L}}\right)$, which provides a measure of the local molecular mobility of the fluid material, according to:

$\mathrm{T}_{2 \mathrm{~L}}=\frac{1}{\pi \Delta \mathrm{H}^{1 / 2}}$

The higher the $T_{2 L}$ value the greater the mobility of the fluid $H$. In some instances, coals with similar fractions of fluid hydrogen have been found to possess different mobility indicating differences in the chemical composition of the fluid entities. High-temperature ${ }^{1} \mathrm{H}$ NMR analyses were carried out at least in duplicate to ensure reproducibility in the results. Reduction in mineral matter concentration in the $<53 \mu \mathrm{m}$ and 53-212 $\mu \mathrm{m}$ size fractions of Indian non-coking coal A2 was achieved through the sink-float method. Sequential sink-float tests were conducted for the coal samples using organic liquid mixtures (benzene, carbon tetrachloride and bromoform) having a specific gravity ranging from 1.3 to 2.0 with an increment of 0.1. The sink-float products were washed, dried, weighed and analyzed. The partially demineralized samples were characterized through solid-state CP/MAS ${ }^{13} \mathrm{C}$ NMR, TGA, high-temperature rheometry and high-temperature ${ }^{1} \mathrm{H}$ NMR. 


\section{Results and Discussion}

3.1. Structural characterization and pyrolysis behavior of the coals

Fig. 1 shows the solid-state CP/MAS ${ }^{13} \mathrm{C}$ NMR spectra of the 53-212 $\mu \mathrm{m}$ size fraction of the coals. The spectra are characterized by an aromatic peak whose maximum is positioned at around $130 \mathrm{ppm}$, an aliphatic peak whose maximum is positioned at $30 \mathrm{ppm}$ and two spinning sidebands positioned at equal distances from the aromatic peak (one at $30 \mathrm{ppm}$ and the other at $230 \mathrm{ppm}$ ). These spinning sidebands arise from aromatic carbon and the distance to the aromatic peak is directly related to the sample spinning rate during analysis (i.e. spinning sidebands appear further away from the aromatic peak at faster spinning rates). Therefore, the areas of the aromatic peak and the two spinning sidebands correspond to the total aromatic carbon. The area of the aliphatic peak minus the area of the overlapping sideband is equivalent to the total aliphatic carbon. The peak positioned at $3.5 \mathrm{ppm}$ in some spectra corresponds to the internal standard tetrakis(trimethylsilyl)silane (TKS).

Indian non-coking coals A1 and A2 discern from the other coals in that they present a clear shoulder in the aromatic peak at around $155 \mathrm{ppm}$ and a small peak at around $180 \mathrm{ppm}$. The shoulder at $155 \mathrm{ppm}$ could originate from phenol O-H (148-158 ppm) and aromatic carbons bound to oxygen, hydroxy, methoxy and oxygen atoms of diphenyl ether groups (148-171 ppm) [24]. The small peak at around $180 \mathrm{ppm}$ could arise from carbonyls in aldehydes, quinones and phenyl ketones. These oxygen-containing functional groups can take part in the formation of cross-links within the coal macromolecule during pyrolysis [25].

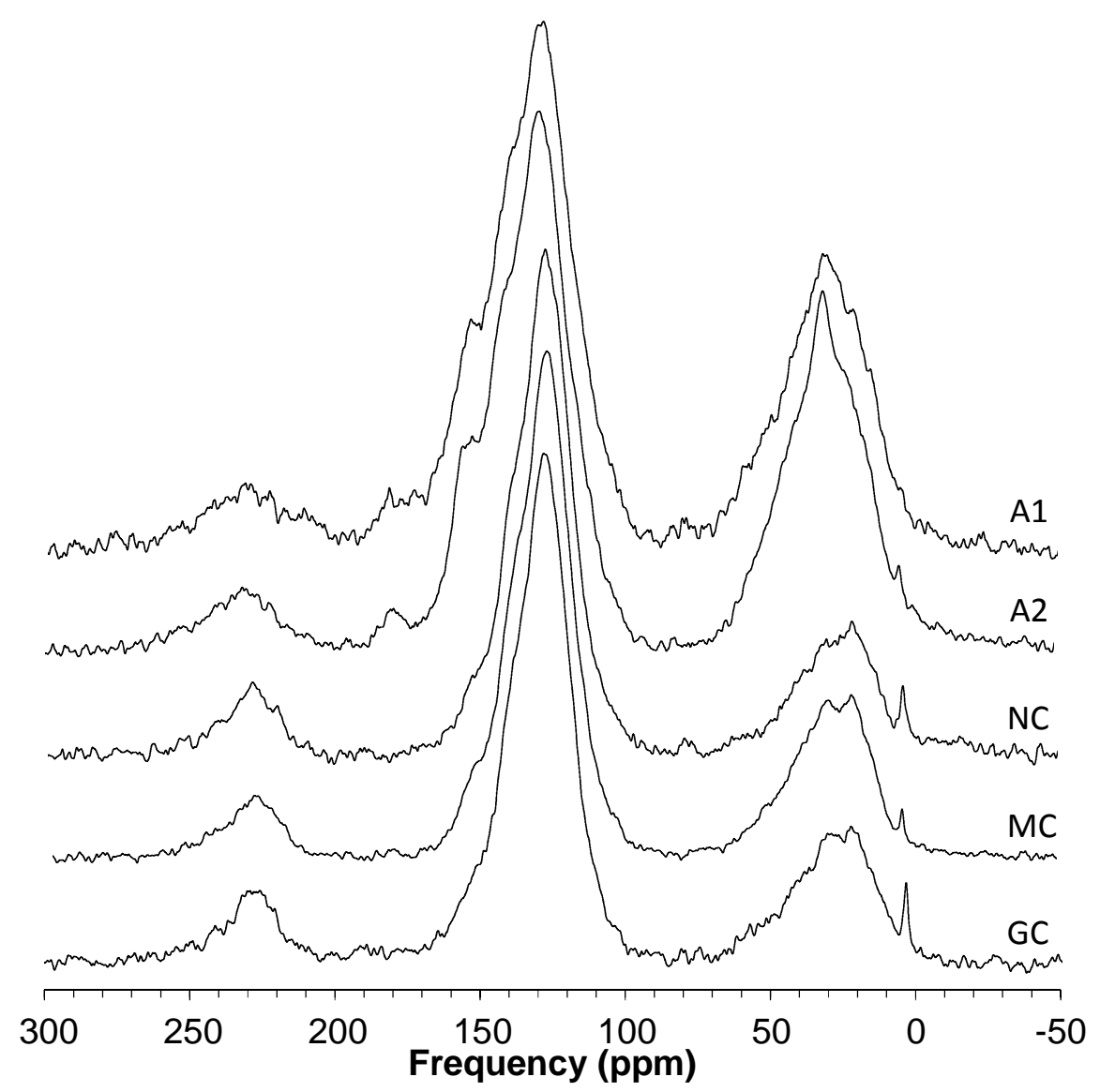

Fig. 1. Solid-state CP/MAS ${ }^{13} \mathrm{C}$ NMR spectra of the $53-212 \mu \mathrm{m}$ size fraction of the coals. 
The aromaticity of the two size fractions of the coals $(<53 \mu \mathrm{m}$ and 53-212 $\mu \mathrm{m})$ were calculated by dividing the total aromatic carbon by the areas of aromatic and aliphatic carbons and the results are presented in Table 4. Within experimental error $( \pm 1 \%)$, the aromaticity values are almost identical in both size fractions. The Indian non-coking coal A2 possesses the lowest fraction of aromatic carbon (ca. 0.75). The non-coking coal NC and good coking coal GC possess the highest aromaticity $(\geq 0.85)$. Indian non-coking coal A1 and medium coking coal MC have similar distributions of aromatic and aliphatic carbon structures.

Table 4. Aromaticity values derived from the integration of CP/MAS ${ }^{13} \mathrm{C}$ NMR spectra.

\begin{tabular}{lccccc}
\hline Size fraction & A1 & A2 & NC & MC & GC \\
\hline$<53 \mu \mathrm{m}$ & 0.77 & 0.72 & 0.91 & 0.77 & 0.85 \\
$53-212 \mu \mathrm{m}$ & 0.75 & 0.71 & 0.86 & 0.79 & 0.85 \\
\hline
\end{tabular}

The devolatilization behavior of the $<53 \mu \mathrm{m}$ and 53-212 $\mu \mathrm{m}$ size fractions of Indian noncoking coals A1 and A2 were determined through thermogravimetric analysis. The devolatilization profiles and the differential weight loss as a function of temperature are presented in Fig. 2. The devolatilization peak at temperatures below $100{ }^{\circ} \mathrm{C}$ can mainly be ascribed to water removal from the samples. Above $200{ }^{\circ} \mathrm{C}$, coal A1 shows three peaks in the DTG profiles at around $420{ }^{\circ} \mathrm{C}, 470{ }^{\circ} \mathrm{C}$ and $570{ }^{\circ} \mathrm{C}$ whereas coal A2 only show distinctive peaks at $420^{\circ} \mathrm{C}$ and $570{ }^{\circ} \mathrm{C}$. The DTG profile for the $53-212 \mu \mathrm{m}$ size fraction of coal A2 is very similar to that found by Biswas et al. [26] during combustion of a low ash (21.1 wt \%) Indian coal. These authors suggested that the double peaks could arise from different burning characteristics of the high proportions of vitrinite and inertinite macerals. Regarding coal A1, the results are very similar for both size fractions. In the case of coal A2, the finer $<53 \mu \mathrm{m}$ size fraction shows higher devolatilization at $420^{\circ} \mathrm{C}$ than the larger $53-212$ $\mu \mathrm{m}$ size fraction. A possible explanation for these results is that there is higher exposure of mineral matter on the surface of the finer particles [22], which acts as catalyst favoring the devolatilization of coal constituents at this temperature. The devolatilization rate at $570{ }^{\circ} \mathrm{C}$ is similar in both size fractions and in both coals (ca. $\left.0.11 \% /{ }^{\circ} \mathrm{C}\right)$. The higher alkalinity index of coal A2 (2.66\%) compared to that of coal A1 (1.91\%) could explain the higher devolatilization rate of the finer $<53 \mu \mathrm{m}$ size fraction at $420{ }^{\circ} \mathrm{C}$. 

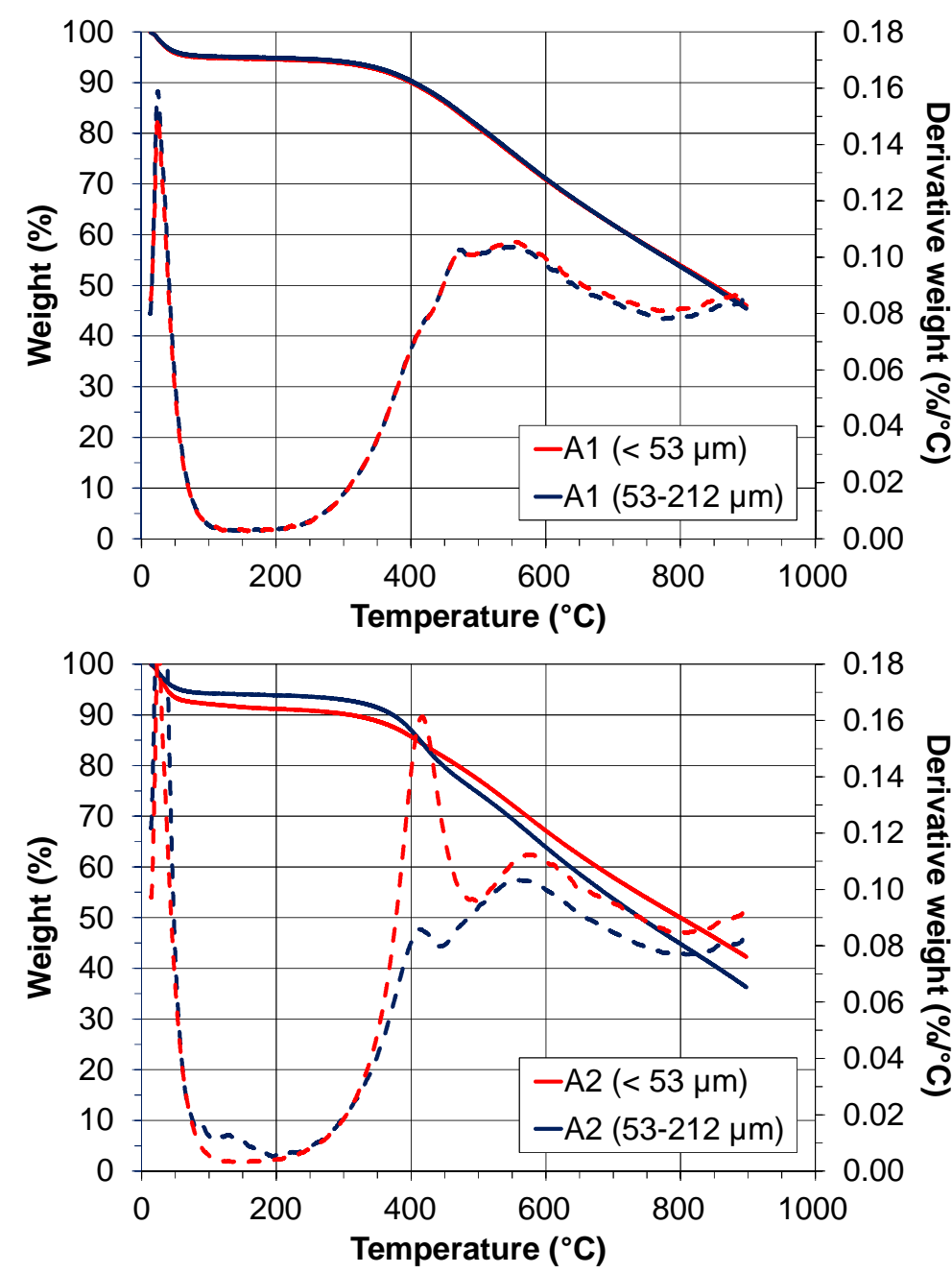

Fig. 2. TGA/DTG profiles of the $<53 \mu \mathrm{m}$ and 53-212 $\mu \mathrm{m}$ size fractions of Indian noncoking coals A1 and A2.

Fig. 3 displays the rheological behavior of the high ash (> $20 \mathrm{wt} \% \mathrm{db}$ ) Indian non-coking coals A1 and A2. Coal A1 does not soften nor expand/collapse in the thermoplastic temperature range of coal $\left(400-500{ }^{\circ} \mathrm{C}\right)$. Only small changes in complex viscosity and plate gap are observed for the non-coking coal A2. The phase angles for these two non-coking coals are below $35^{\circ}$ confirming their solid or gel-like behavior. 

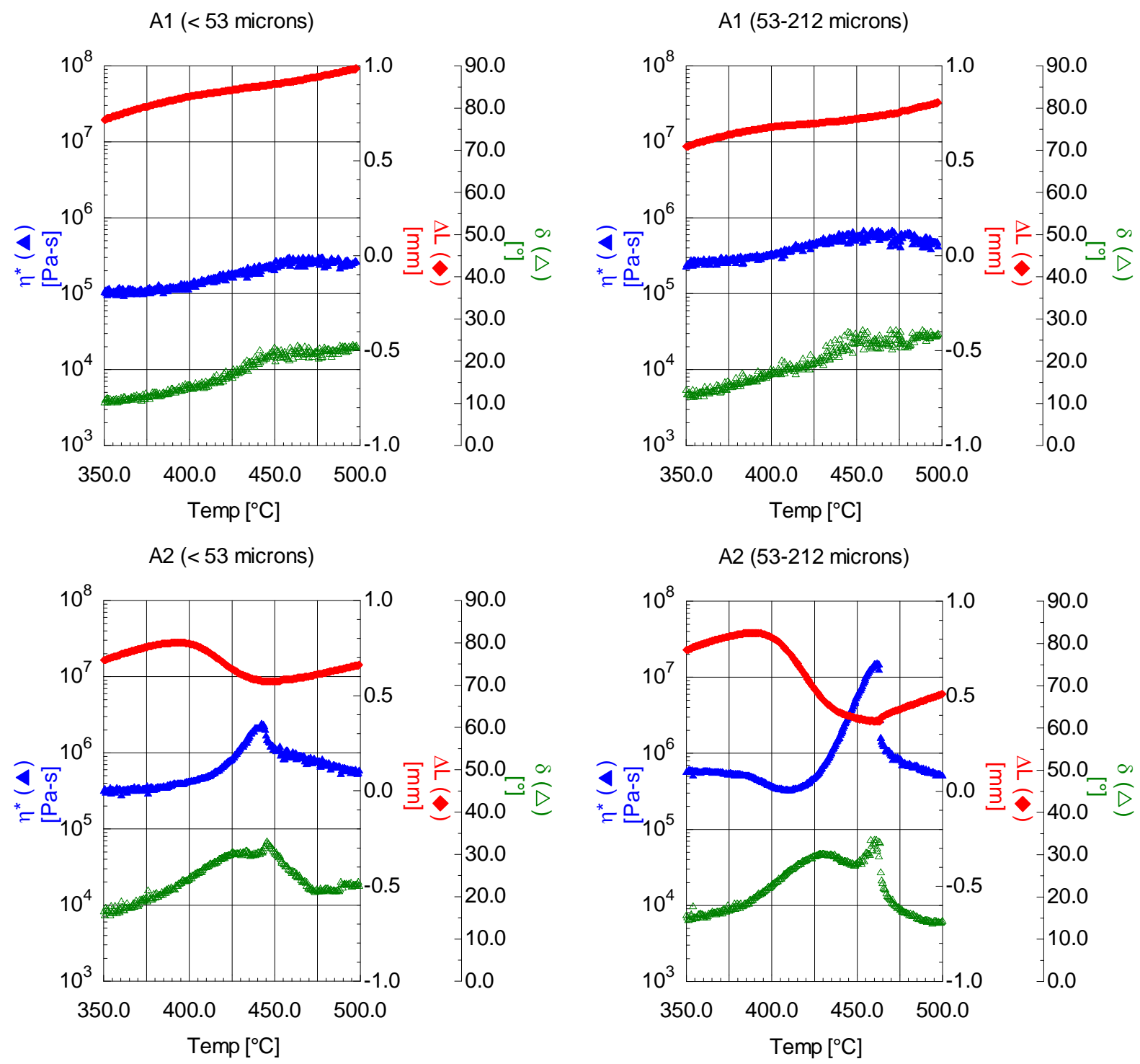

Fig. 3. Complex viscosity $\left(\eta^{*}\right)$, change in plate gap $(\triangle \mathrm{L})$ and phase angle $(\delta)$ as a function of temperature for the two size fractions of high ash Indian non-coking coals A1 and A2.

Fig. 4 compares the rheological behavior of the reference non-coking coal NC, medium coking coal MC and good coking coal GC studied. The non-coking coal NC shows no clear decrease in complex viscosity or significant change in the plate gap for both size fractions investigated. As expected, the good and medium coking coals display large reductions in complex viscosity at maximum fluidity $\left(<10^{5} \mathrm{~Pa}\right.$.s $)$ and high values of phase angle $\left(>55^{\circ}\right)$. With the exception of the $<53 \mu \mathrm{m}$ size fraction of good coking coal GC, which shows almost the same extent of mass expansion and contraction, there is significant mass contraction (> $35 \%$ reduction of the initial disc thickness) in the other size fractions of these two coals. 

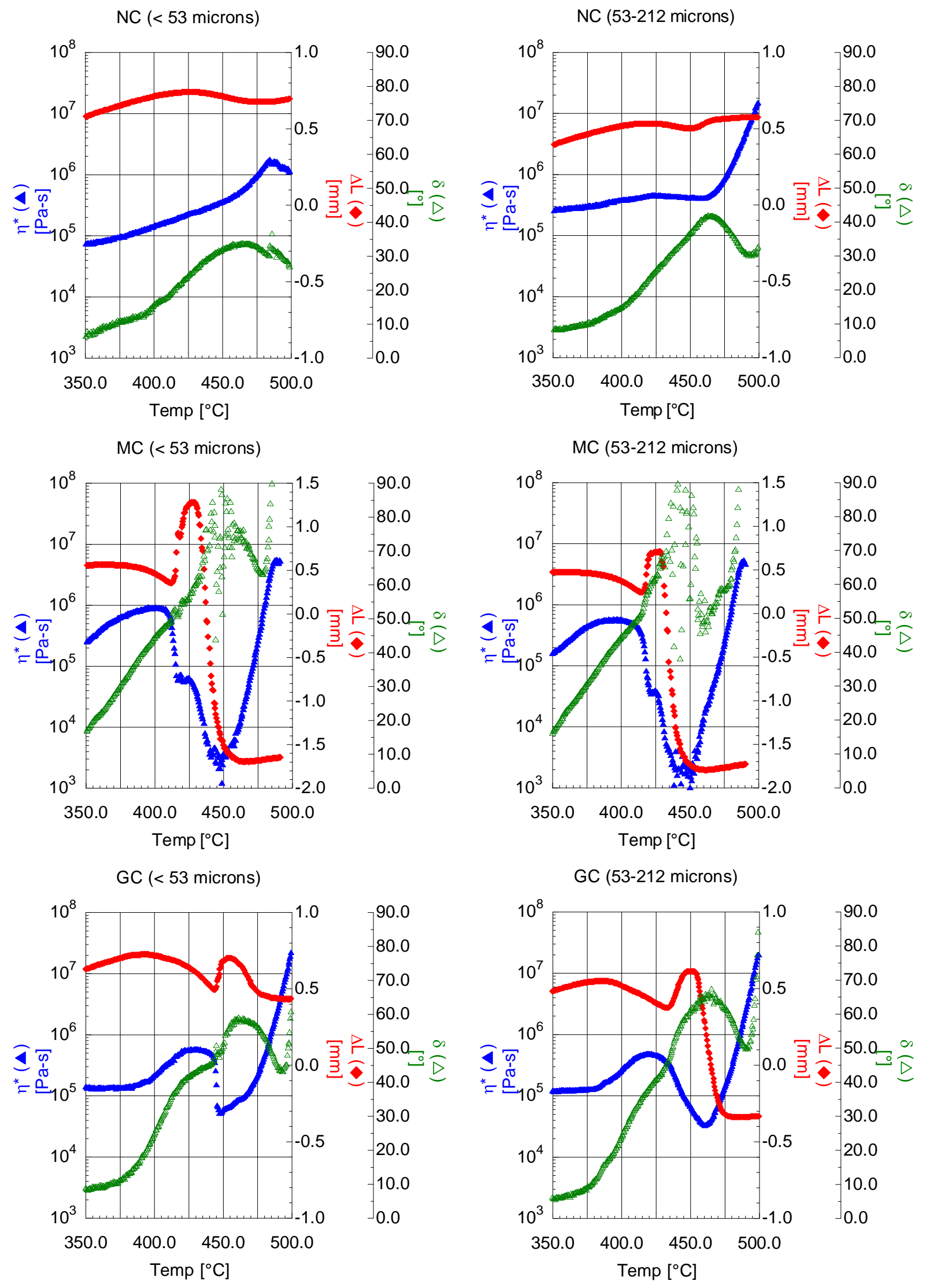
Fig. 4. Complex viscosity $\left(\eta^{*}\right)$, change in plate gap $(\Delta \mathrm{L})$ and phase angle $(\delta)$ as a function of temperature for the two size fractions of non-coking coal $\mathrm{NC}$, medium coking coal $\mathrm{MC}$ and good coking coal GC.

High-temperature ${ }^{1} \mathrm{H}$ NMR results for the two Indian non-coking coals (A1 and A2) and the three reference coals (NC, MC and GC) are presented in Figs. 5 and 6. In these figures, the percentage of fluid $\mathrm{H}$ for the two size fractions of the coals and the spin-spin relaxation time of the fluid $\mathrm{H}\left(\mathrm{T}_{2 \mathrm{~L}}\right)$, which provides a measure of the local molecular mobility of the fluid material, are expressed as a function of temperature. Fig. 5 displays the results for the $<53$ $\mu \mathrm{m}$ size fraction of the coals. As expected, high concentrations of fluid $\mathrm{H}$ are observed for the medium and good coking coals MC and GC. But this is also observed in the high ash Indian non-coking coal A2. The high ash coal A2 shows a maximum in fluid $\mathrm{H}$ at lower temperature $\left(445^{\circ} \mathrm{C}\right)$ than coals $\mathrm{MC}$ and $\mathrm{GC}\left(\geq 460^{\circ} \mathrm{C}\right)$ consistent with its higher volatile matter content or lower rank. The other Indian non-coking coal A1 and reference non-coking coal NC display low concentrations of fluid $\mathrm{H}(<25 \%)$ consistent with their high complex viscosities $\left(>10^{5} \mathrm{~Pa} . \mathrm{s}\right)$ and low phase angle values $\left(<45^{\circ}\right)$ characteristic of predominantly solid-like viscoelastic materials. For these two least fluid coals in terms of the amount of mobile $\mathrm{H}$ generated, the trends and values of the two size fractions are fairly similar and there is no clear maximum in the percentage of fluid $\mathrm{H}$. Regarding the mobility of the fluid $\mathrm{H}$, as denoted by $\mathrm{T}_{2 \mathrm{~L}}$, Indian non-coking coal $\mathrm{A} 2$ shows the highest mobility value in the coal series $(153 \mu \mathrm{s})$. The other Indian non-coking coal A1 also displays relatively high $\mathrm{T}_{2 \mathrm{~L}}$ values (88 $\mu \mathrm{s})$.
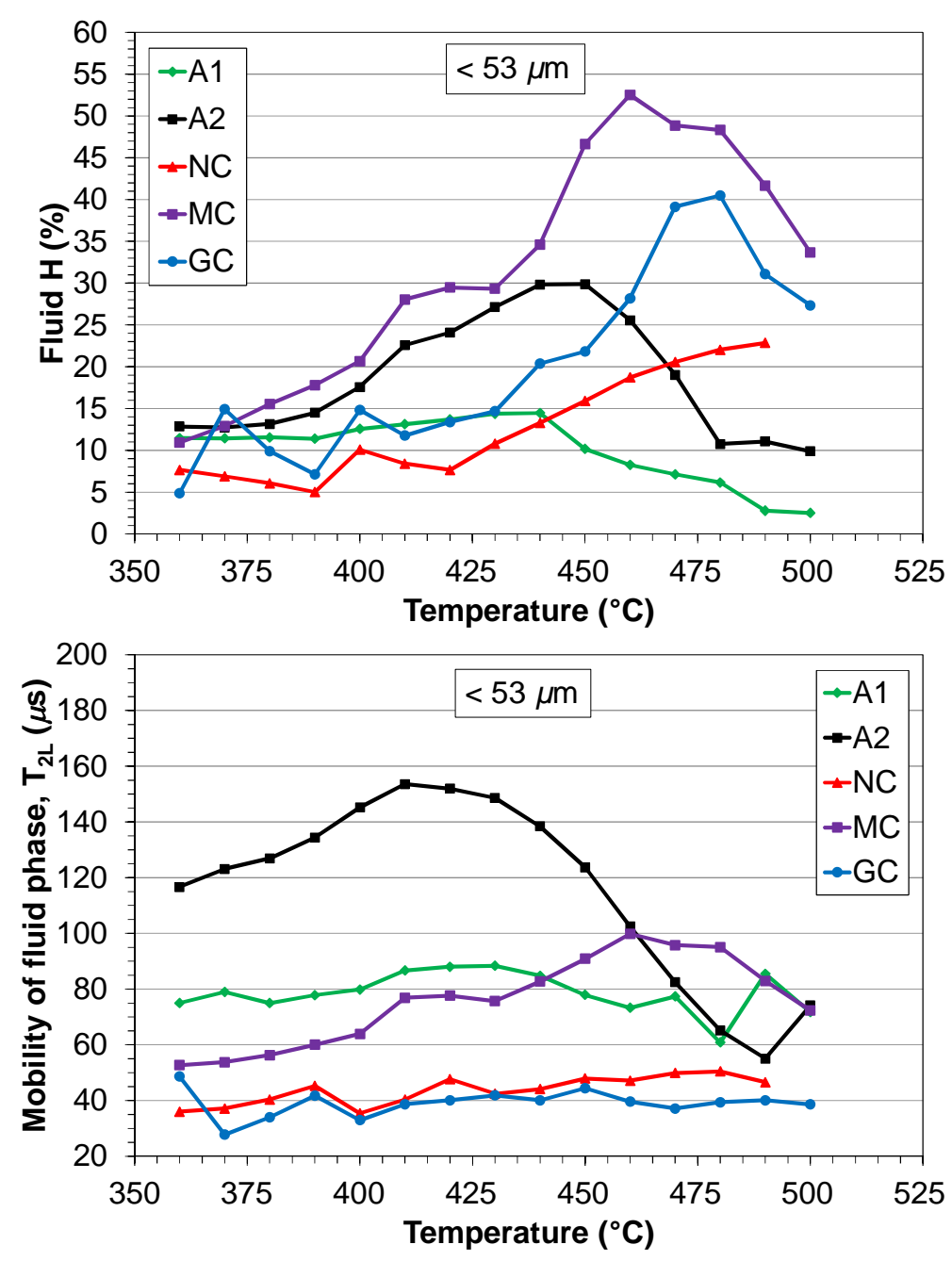
Fig. 5. Percentage of fluid $\mathrm{H}$ and its mobility for the $<53 \mu \mathrm{m}$ size fraction of the coals.

Fig. 6 displays the results for the 53-212 $\mu \mathrm{m}$ size fraction of the coals. These results and those in Fig. 5 indicate that the finer $<53 \mu \mathrm{m}$ size fractions of coals A2 and MC develop less fluid material that the larger 53-212 $\mu \mathrm{m}$ size fractions. The amount of fluid $\mathrm{H}$ in the other coals (A1, NC and GC) is similar in both size fractions. The maximum mobility displayed by the larger 53-212 $\mu \mathrm{m}$ size fraction of coal A2 $(185 \mu \mathrm{s})$ is also significantly higher than that for the finer $<53 \mu \mathrm{m}$ size fraction $(153 \mu \mathrm{s})$. The same can be said for the maximum mobilities of the fluid material in the 53-212 size fractions of coals NC and GC, which are $30-45 \mu$ s higher than those in the finer fractions. The maximum mobilities displayed by the larger 53-212 $\mu \mathrm{m}$ size fractions of coals A1 and MC are just 5-10 $\mu$ s higher than those for the finer fractions. Therefore, Indian non-coking coal A2 possesses the unique characteristics of high amount and high mobility of fluid $\mathrm{H}$, which resemble those of a medium coking coal, despite its gel-like character. The combination of high concentration $(40 \%)$ and mobility (ca. $180 \mu \mathrm{s}$ ) of fluid $\mathrm{H}$ in the 53-212 $\mu \mathrm{m}$ size fractions of coal A2 could be responsible for the previously observed minimum in complex viscosity (Fig. 3). Although displaying a low concentration of fluid $\mathrm{H}$, the mobility of the fluid phase for the other high ash Indian coal A1 is still high (ca. $100 \mu \mathrm{s}$ ).
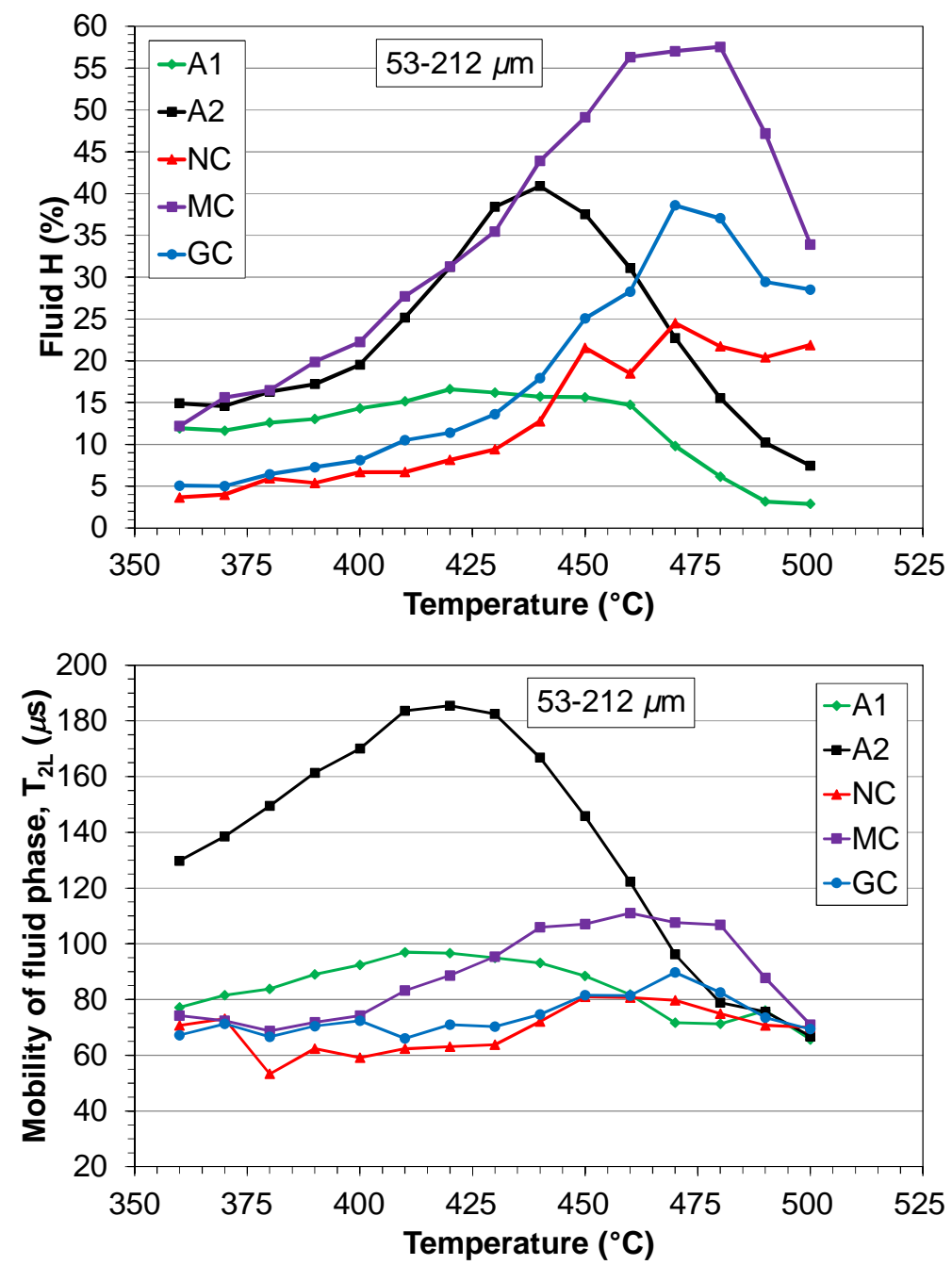

Fig. 6. Percentage of fluid $\mathrm{H}$ and its mobility for the 53-212 $\mu \mathrm{m}$ size fraction of the coals. 
Considering that the chemical structures in the 53-212 size fraction of the two high ash Indian non-coking coals are very similar, as revealed by the CP/MAS ${ }^{13} \mathrm{C}$ NMR spectra (Fig. 1), the most likely explanation for the apparent abnormal behavior of the high ash non-coking coal A2 in terms of having high viscosity but still containing a high concentration of fluid $\mathrm{H}$ is that the mineral matter prevents bulk movement in the sample but the local mobility of the fluid phase is still high on the nanometer scale that ${ }^{1} \mathrm{H}$ NMR detects.

\subsection{Viscoelastic behavior of blends made of Indian non-coking and medium coking coals} The 53-212 $\mu \mathrm{m}$ size fractions of the high ash Indian non-coking coals A1 and A2 were blended with the 53-212 $\mu \mathrm{m}$ size fraction of medium coking coal MC to determine the effect of the high ash coals on the minimum complex viscosity developed by the blends. In the past, it has been proven that blends of two coals that do show synergistic effects on fluidity development follow the polymer blend rule [17], which states that the minimum complex viscosity of the blend can be predicted from the minimum complex viscosity values of the single coals using the following logarithmic relationship:

$\ln \left(\eta^{*}\right)=\Phi_{1} \ln \left(\eta_{1}^{*}\right)+\Phi_{2} \ln \left(\eta_{2}^{*}\right)$

where $\eta^{*}$ is the minimum complex viscosity value of the blend, $\Phi_{1}$ and $\Phi_{2}$ are the fractions of coal 1 and coal 2 in the blend, and $\eta^{*}{ }_{1}$ and $\eta^{*}{ }_{2}$ are the minimum complex viscosity values of the individual coals. The polymer blend rule has been used here to calculate the minimum complex viscosities of the different binary blends. Indian non-coking coal A2 shows a minimum in complex viscosity of $3.26 \times 10^{5} \mathrm{~Pa}$.s at $410^{\circ} \mathrm{C}$ but coal A1 does not show a clear minimum in complex viscosity. Since coals A1 and A2 come from the same coal mine but from different seams, it was assumed that the minimum complex viscosity of the Indian noncoking coal A1 also appears at $410{ }^{\circ} \mathrm{C}$. According to this hypothesis, Fig. 3 shows that the minimum complex viscosity value for the 53-212 $\mu \mathrm{m}$ size fraction of coal A1 is around 3.6 $\times 10^{5}$ Pa.s. The results are presented in Fig. 7 , where the continuous black lines were obtained using the polymer blend rule (Eq. 3) and the dash grey lines were obtained from experimental data. The results for the blends containing $25 \mathrm{wt} \%$ and $50 \mathrm{wt} \%$ of non-coking coal clearly indicate that coal A1 causes a more deleterious effect on the fluidity of medium coking coal MC than coal A2. These findings cannot be rationalized by the chemical properties of coal A1 since this coal yields less ash and volatiles (on a dry ash free basis) than coal A2. It could be hypothesized that the high mineral matter content in both coals restricts bulk flow but some of the structural entities present in coal A2, which are responsible for the high amount and extreme mobility $\left(\mathrm{T}_{2 \mathrm{~L}}\right)$ of fluid $\mathrm{H}$ in Fig. 6, prevent the destruction of the fluid entities in medium coking coal MC at relatively low concentrations of coal A2 $(\leq 25$ $\mathrm{wt} \%)$. 

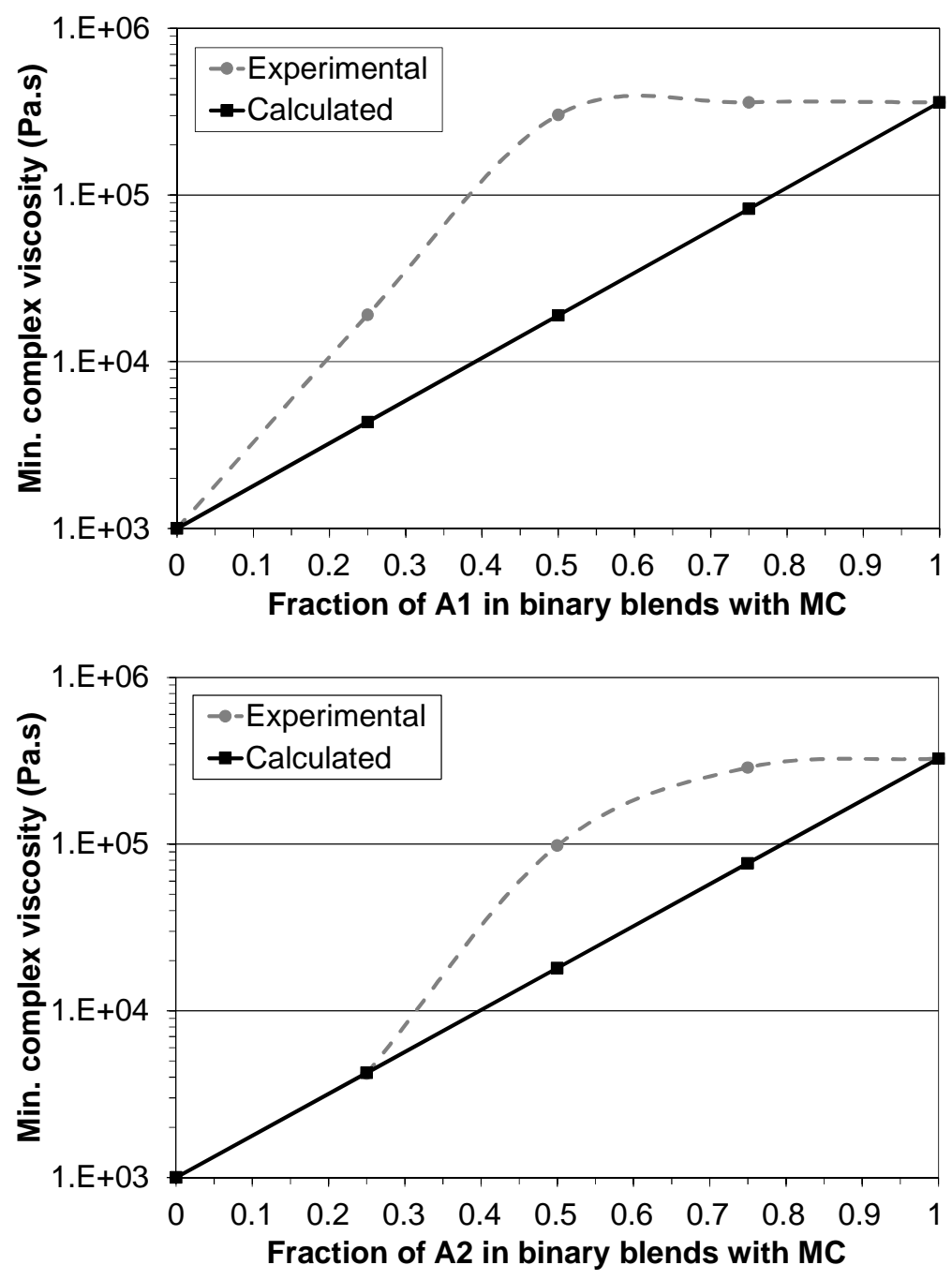

Fig. 7. Experimental and calculated values of the minimum complex viscosity of the blends as a function of their composition.

\subsection{Influence of mineral matter on coal devolatilization and fluidity development}

The mineral matter of Indian non-coking coal A2 was reduced with the sink-float method to achieve ash yields of $17 \mathrm{wt} \%$ (i.e. 54\% ash reduction). The leaner coal was sieved and crushed to obtain the $<53 \mu \mathrm{m}$ and $53-212 \mu \mathrm{m}$ size fractions. The solid-state CP/MAS ${ }^{13} \mathrm{C}$ NMR spectra of the two size fractions of washed coal A2 are shown in Fig. 8. The aromaticity values calculated from these spectra for the $<53 \mu \mathrm{m}$ and 53-212 $\mu \mathrm{m}$ size fractions were respectively 0.68 and 0.69 . These values are fairly similar to those of the untreated coal (ca. 0.71, Table 4) and within the experimental error arising from data processing $( \pm 1 \%)$, indicating that the sink-float method did not alter significantly the carbon structures of the coal constituents. 


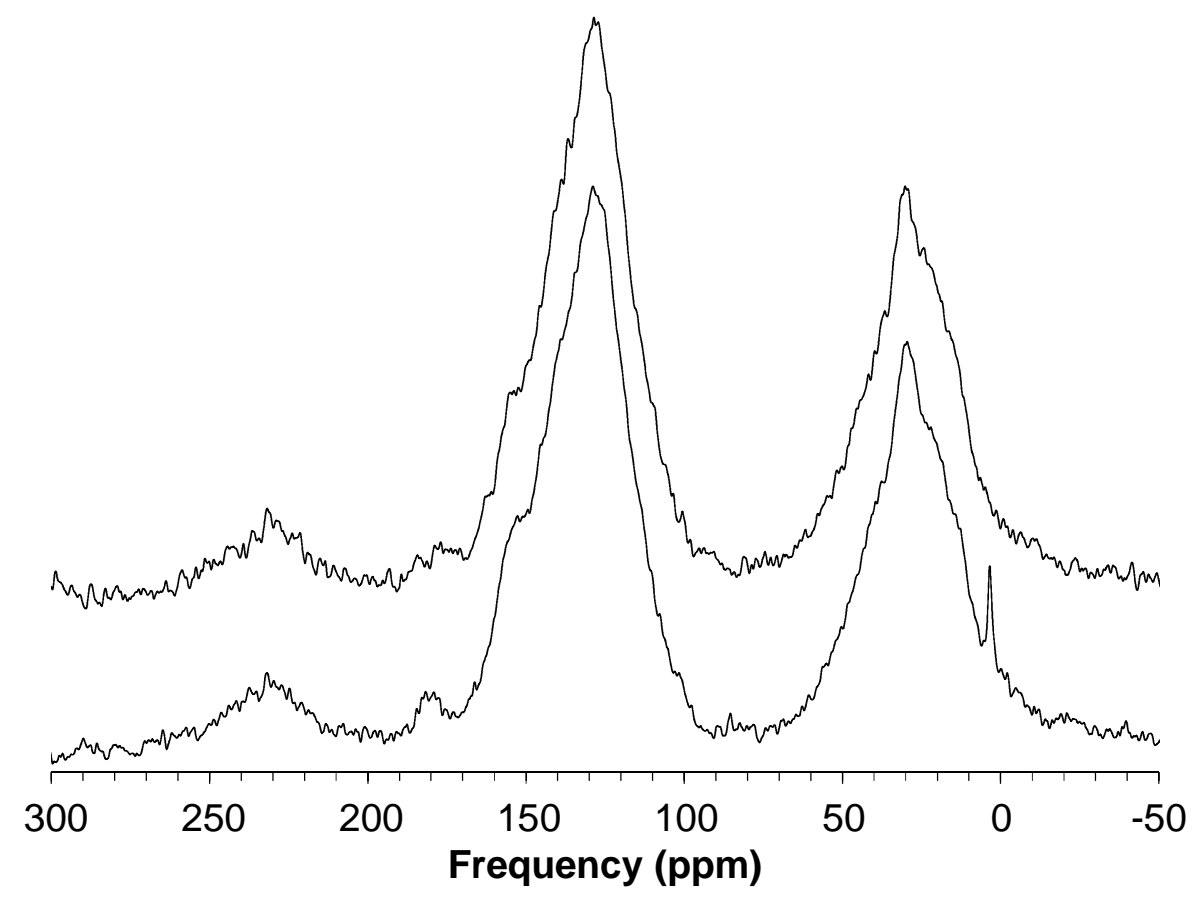

Fig. 8. Solid-state CP/MAS ${ }^{13} \mathrm{C}$ NMR spectra of the $<53 \mu \mathrm{m}$ (top) and 53-212 $\mu \mathrm{m}$ (bottom) size fractions of Indian non-coking coal A2 after sink-float washing.

The devolatilization behavior of these two size fractions obtained from the washed coal A2 is presented in Fig. 9. A comparison of these results with those in Fig. 2 for the parent coal indicates that the reduced ash content in the $<53 \mu \mathrm{m}$ size fraction of the washed coal decreases the devolatilization rate at $420{ }^{\circ} \mathrm{C}$. This finding suggests that the mineral matter in Indian coal A2 only promotes devolatilization reactions in fines $(<53 \mu \mathrm{m})$. It must also be noted that the char yield at $900{ }^{\circ} \mathrm{C}$ decreased by around $3 \%$ with lower mineral matter in the $<53 \mu \mathrm{m}$ size fraction of coal A2. The devolatilization behavior of the larger 53-212 $\mu \mathrm{m}$ size fraction was not affected by the reduction in ash content. 


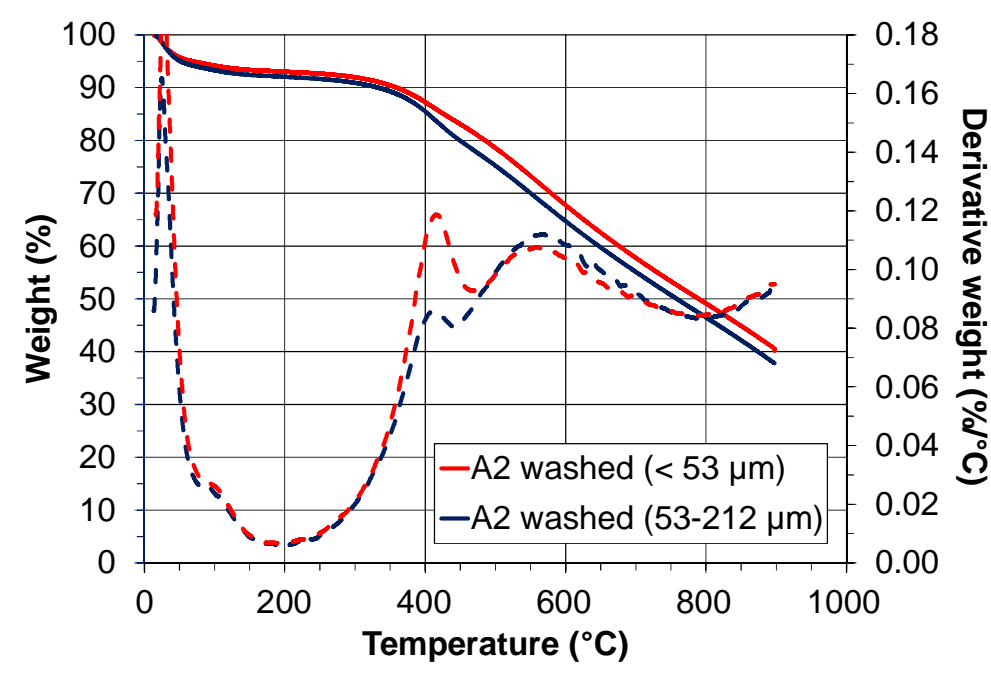

Fig. 9. TGA/DTG profiles of the $<53 \mu \mathrm{m}$ and 53-212 $\mu \mathrm{m}$ size fractions of Indian noncoking coal A2 after sink-float washing.

High-temperature rheometry results for the two size fractions of the washed Indian coal A2 are presented in Fig. 10. As expected, the trends for complex viscosity, phase angle and plate gap are fairly similar regardless of particle size fraction or coal studied. A comparison of these results with those in Fig. 3 indicates that the slightly fluid character of the 53-212 $\mu \mathrm{m}$ size fraction of the parent coal A2 is further reduced by the sink-float method, as clearly indicated by the reduction in the value of the maximum phase angle from $30^{\circ}$ in the parent coal to $20^{\circ}$ in the washed coal.
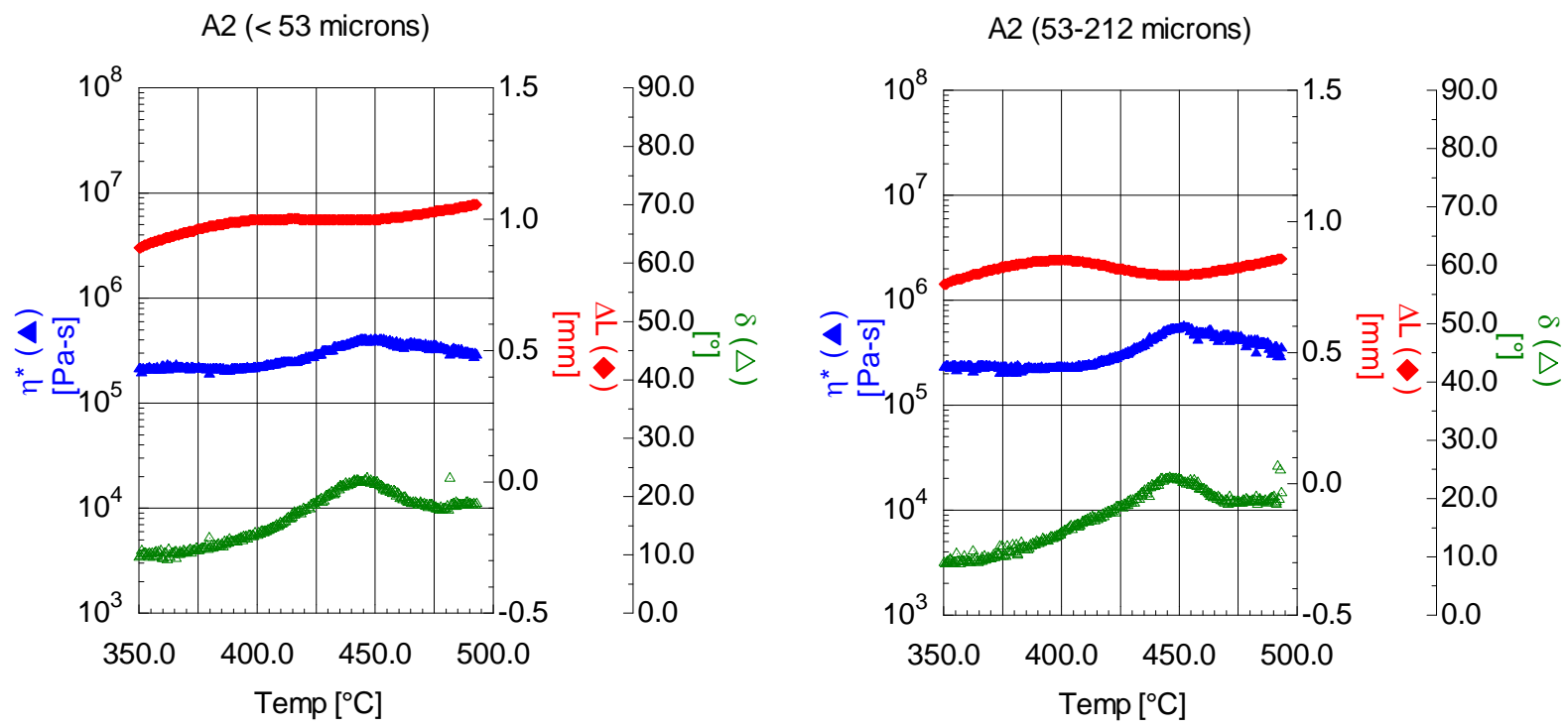

Fig. 10. Complex viscosity $\left(\eta^{*}\right)$, change in plate gap $(\Delta \mathrm{L})$ and phase angle $(\delta)$ as a function of temperature for the two size fractions of the washed non-coking coal A2.

The high-temperature ${ }^{1} \mathrm{H}$ NMR results for the two size fractions of the Indian non-coking coal A2 before and after washing are presented in Figs. 11 and 12. In these figures, the partially demineralized coal is denoted as washed and the results for the parent coal are presented for comparison purposes. In the $<53 \mu \mathrm{m}$ particle size fraction, reduction in 
mineral matter content from $30 \mathrm{wt} \%$ to $17 \mathrm{wt} \%$ causes a reduction in the maximum $\mathrm{T}_{2 \mathrm{~L}}$ by around $60 \mu \mathrm{s}$ and a reduction in the maximum concentration of fluid $\mathrm{H}$ by around $5 \%$. In the 53-212 $\mu \mathrm{m}$ size fraction, the effects are even more pronounced with a reduction in maximum $\mathrm{T}_{2 \mathrm{~L}}$ by around $80 \mu \mathrm{s}$ and reduction in percentage of fluid $\mathrm{H}$ by around $8 \%$. Maroto-Valer et al. [21] found that mild oxidation reduces primarily the concentration of fluid $\mathrm{H}$ and only affects slightly its mobility. Therefore, the drastic reduction in the mobility of the fluid $\mathrm{H}$ in coal A2 cannot be fully ascribed to oxidation during the sink-float treatment. Interestingly, the reduction in ash content from $37 \mathrm{wt} \%$ to $17 \mathrm{wt} \%$ in coal A2 after the treatment reduces the maximum mobility of the fluid $\mathrm{H}$ in the $<53 \mu \mathrm{m}$ and 53-212 $\mu \mathrm{m}$ size fractions to $91 \mu \mathrm{s}$ and $107 \mu \mathrm{s}$, respectively. These levels are comparable to those in the high ash (14 wt $\%)$ Indian non-coking coal A1, i.e. $88 \mu$ s for the $<53 \mu \mathrm{m}$ size fraction and $97 \mu$ s for the 53-212 $\mu \mathrm{m}$ size fraction (Figs. 5 and 6). Therefore, the reduction in mobility could be directly related to the ash yielded by the Indian non-coking coal, whereby higher ash content leads to higher mobility of the fluid $\mathrm{H}$.
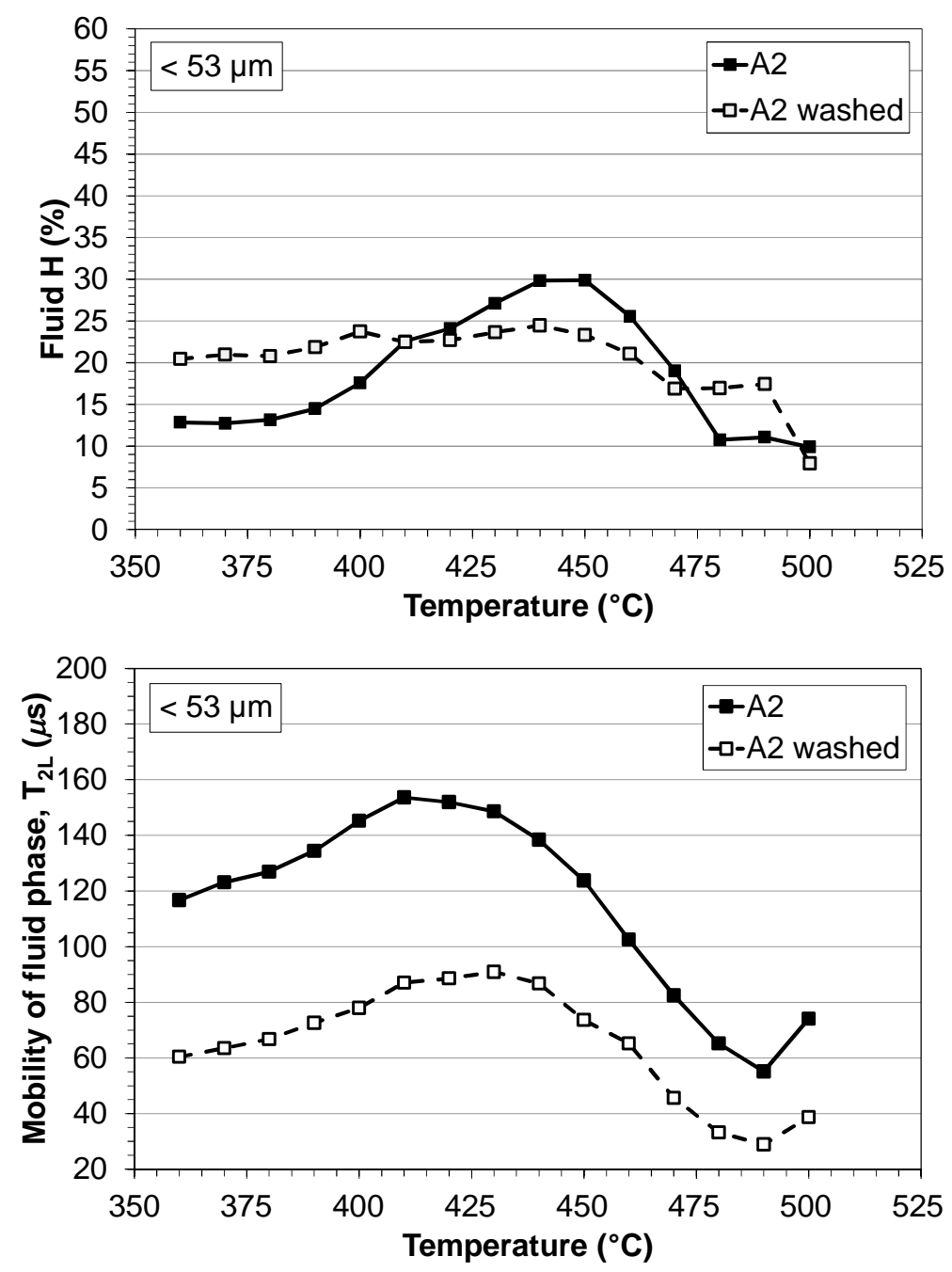

Fig. 11. Percentage of fluid $\mathrm{H}$ and its mobility for the $<53 \mu \mathrm{m}$ size fraction of Indian noncoking coal A2 before and after the sink-float method. 

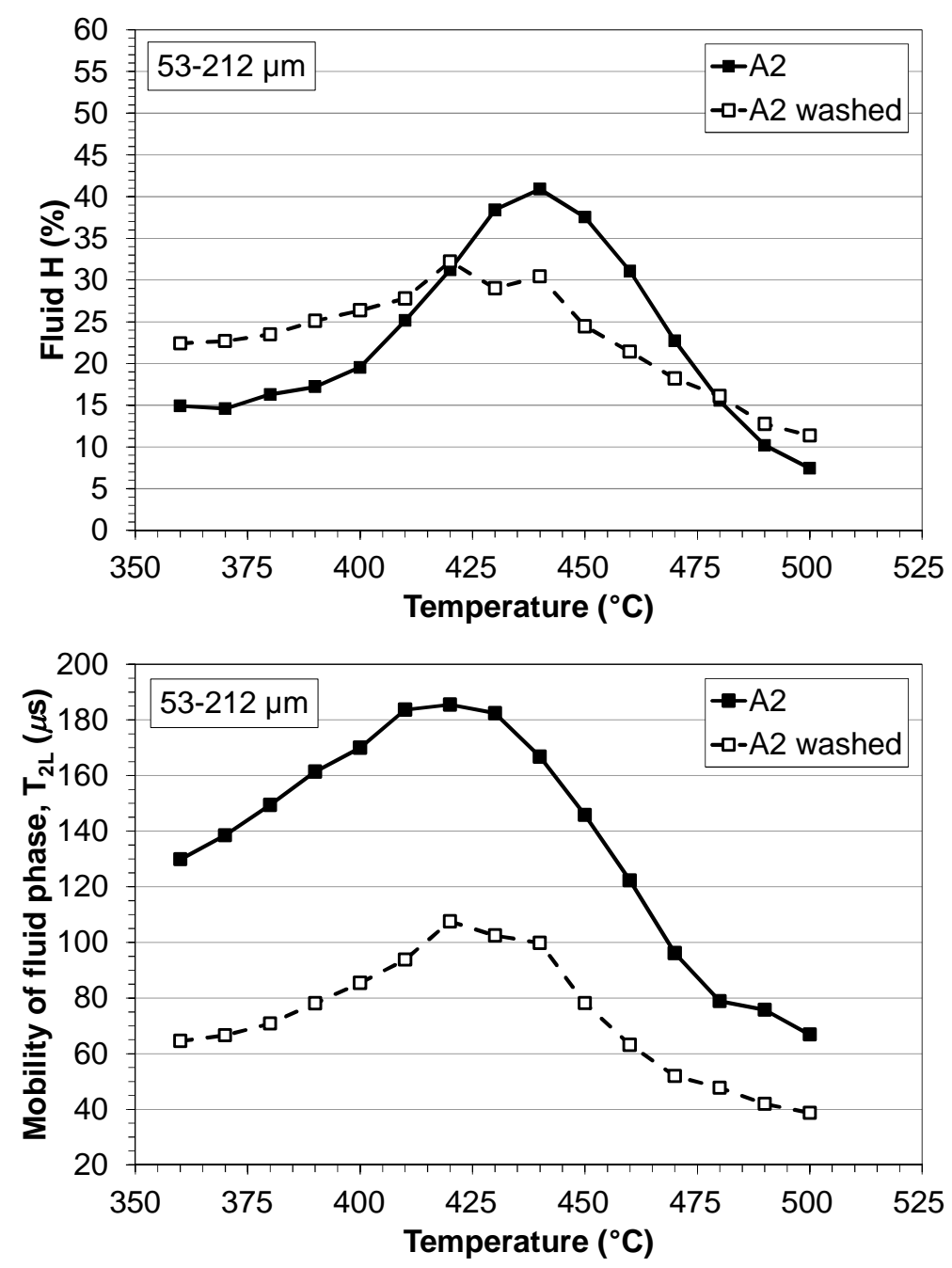

Fig. 12. Percentage of fluid $\mathrm{H}$ and its mobility for the 53-212 $\mu \mathrm{m}$ size fraction of Indian non-coking coal A2 before and after the sink-float method. 


\section{Conclusions}

The $<53 \mu \mathrm{m}$ and 53-212 $\mu \mathrm{m}$ size fractions of two high ash (> $13 \mathrm{wt} \%$ ) Indian non-coking coals and imported non-coking, medium coking and good coking coals were characterized through high-temperature rheometry and ${ }^{1} \mathrm{H}$ NMR to understand the effect of mineral matter of the fluid properties of coals and blends. The Indian non-coking coals investigated did not develop a clear minimum in complex viscosity and the maximum phase angle was below $45^{\circ}$, which is characteristic of predominantly solid or gel-like character. However, the concentration of fluid $\mathrm{H}$ in the high ash non-coking coal $\mathrm{A} 2$ was relatively high and quite similar to that of a good coking coal. Furthermore, the mobility of the fluid $\mathrm{H}$ in coal A2 $\left(\mathrm{T}_{2 \mathrm{~L}}\right.$ $>150 \mu \mathrm{s}$ ) was much greater than in the medium and good coking coals, regardless of the size fraction studied. The likely explanation for this abnormal behavior is that the mineral matter prevents bulk movement in the sample but the local mobility of the fluid phase is still high on the nanometer scale that ${ }^{1} \mathrm{H}$ NMR detects. Blending the 53-212 $\mu$ m fraction of the two Indian non-coking coals with the same size fraction of the highly fluid medium coking coal gave higher viscosities (i.e. lower fluidity) than predicted by the polymer blend rule, probably again due to the high mineral matter restricting bulk flow. This negative effect was less pronounced with the higher ash Indian coal (37 wt \%). The 53-212 $\mu \mathrm{m}$ fraction of this coal was characterized by high mobility $\left(\mathrm{T}_{2 \mathrm{~L}}>180 \mu \mathrm{s}\right)$ of its fluid phase. These highly mobile entities might interact positively with the fluid entities evolving from the medium coking coal. Partial demineralization of the high ash Indian non-coking coal to $17 \mathrm{wt} \%$ through the sink-float method did not decrease the complex viscosity of the coal but reduced the maximum mobility of the fluid $H$ to levels observed with the lower ash content (14 wt \%) Indian coal. Therefore, this reduction in mobility could be directly related to the ash yielded by the Indian non-coking coal.

\section{Acknowledgement}

The authors thank Tata Steel Limited for providing financial support for this study.

\section{References}

[1] Ministry of Coal. Government of India. https://coal.nic.in/content/coal-reserves.

[2] D. Nag, B. Das, P.S. Dash, S. Sen, S. Paul, S. Verma, S.K. Haldar, Use of phenolic resin in coke making at Tata Steel, Ironmaking Steelmaking 44 (2017) 526-531.

[3] R. Alvarez, C. Barriocanal, M.A. Díez, J.L.G. Cimadevilla, M.D. Casal, C.S. Canga, Recycling of hazardous waste materials in the coking process, Environ. Sci. Technol. 38 (2004) 1611-1615.

[4] D.L. Khoury, Coal clean technology, Noyes Data Corporation, Park Ridge, NJ, USA, 1981.

[5] B.K. Mishra, B. Das, S.K. Biswal, P.S.R. Reddy, Overview of beneficiation, utilization and environmental issues in relation to coal processing, Proc. Indian Nat. Sci. Acad. 81 (2015) 725-737.

[6] N. Tsubouchi, Y. Ohtsuka, Formation of $\mathrm{N}_{2}$ during pyrolysis of Ca-loaded coals, Fuel 81 (2002) 1423-1431.

[7] M.R. Khan, R.G. Jenkins, Influence of added calcium compounds on swelling, plastic, and pyrolysis behaviour of coal devolatilized at elevated pressures, Fuel 65 (1986) 1203-1208.

[8] J.W. Patrick, F.H. Shaw, Influence of sodium carbonate on coke reactivity, Fuel 51 (1972) 69-75. 
[9] M.R. Khan, R.G. Jenkins, Swelling and plastic properties of coal devolatilized at elevated pressures of $\mathrm{H}_{2}$ and He: Influence of potassium and silicon additives, Fuel 65 (1986) 1291-1299.

[10] J. Kaczorowski, T. Lindstad, M. Syvertsen, The influence of potassium on the Boudouard reaction in manganese production, ISIJ Intern. 47 (2007) 1599-1604.

[11] V.N. Misra, P.S.R. Reddy, S.K. Biswal, Beneficiation of non-coking coal for metallurgical purposes, CCAI Monthly New Letter (2003) May 27-36.

[12] N. Vasumathi, T.V. Vijaya Kumar, S. Ratchambigai, S. Subba Rao, S. Prabhakar, G. Bhaskar Raju, Beneficiation of an Indian non-coking coal by column flotation, Int. J. Coal Sci. Technol. 3 (2016) 206-214.

[13] R. Singh, S. Dey, N. Sinha, Performance of different classes of organic compounds as frother in de-ashing of Indian coking coal by froth flotation, Trans. Indian Inst. Metals 70 (2017) 433-442.

[14] S.D. Barma, Satish R, P.K. Baskey, S.K. Biswal, Chemical beneficiation of high ash Indian non-coking coal by alkali leaching under low-frequency ultrasonication, Energy Fuel (2018) just accepted manuscript (doi: 10.1021/acs.energyfuels.7b03291).

[15] K.M. Steel, M. Castro Díaz, J.W. Patrick, C.E. Snape, Use of rheometry and ${ }^{1}$ H NMR spectroscopy for understanding the mechanisms behind the generation of coking pressure, Energy Fuel 18 (2004) 1250-1256.

[16] M.C. Díaz, K.M. Steel, T.C. Drage, J.W. Patrick, C.E. Snape, Determination of the effect of different additives in coking blends using a combination of in situ hightemperature ${ }^{1} \mathrm{H}$ NMR and rheometry, Energy Fuel 19 (2005) 2423-2431.

[17] K.M. Steel, M.C. Díaz, J.W. Patrick, C.E. Snape, Evidence for network formation during the carbonization of coal from the combination of rheometry and ${ }^{1} \mathrm{H}$ NMR techniques, Fuel 85 (2006) 1821-1830.

[18] M.C. Díaz, L. Edecki, K.M. Steel, J.W. Patrick and C.E. Snape, Determination of the effects caused by different polymers on coal fluidity during carbonization using hightemperature ${ }^{1}$ H NMR and rheometry, Energy Fuel 22 (2008) 471-479.

[19] M. Castro Díaz, H. Zhao, S. Kokonya, A. Dufour, C.E. Snape, The effect of biomass on fluidity development in coking blends using high-temperature SAOS rheometry, Energy Fuel 26 (2012) 1767-1775.

[20] S. Kokonya, M. Castro Díaz, C. Barriocanal, C.E. Snape, An investigation into the effect of fast heating on fluidity development and coke quality for blends of coal and biomass, Biomass Bioenergy 56 (2013) 295-306.

[21] M.M. Maroto-Valer, J.M. Andrésen, C.E. Snape, In-situ ${ }^{1}$ H NMR investigation of particle size, mild oxidation, and heating regime effects on plasticity development during coal carbonization, Energy Fuel 11 (1997) 236-244.

[22] M.V. Kök, E. Özbas, O. Karacan, C. Hicyilmaz, Effect of particle size on coal pyrolysis, J. Anal. Appl. Pyrolysis 45 (1998) 103-110.

[23] M.S. Jena, S.K. Biswal, M.V. Rudramuniyappa, Study on flotation characteristics of oxidized Indian high ash sub-bituminous coal, Int. J. Miner. Process. 87 (2008) 42-50.

[24] D.E. Axelson, Solid state nuclear magnetic resonance of fossil fuels: an experimental approach. Multiscience Publications Limited, Montreal, Canada, 1985.

[25] P.R. Solomon, M.A. Serio, G.V. Despande, E. Kroo, Cross-linking reactions during coal conversion, Energy Fuel 4 (1990) 42-54.

[26] S. Biswas, N. Choudhury, P. Sarkar, A. Mukherjee, S.G. Sahu, P. Boral, A. Choudhury, Studies on the combustion behavior of blends of Indian coals by TGA and Drop Tube Furnace, Fuel Process. Technol. 87 (2006) 191-199. 